\title{
Association between digital dermatitis lesions and test-day milk yield of Holstein cows from 41 French dairy farms
}

\author{
A. Relun, ${ }^{\star} † \ddagger$ A. Lehebel, $\dagger$ A. Chesnin, $\downarrow \ddagger$ R. Guatteo, $\nmid \ddagger^{1}$ and N. Bareille $\ddagger$ \\ ${ }^{*}$ French Livestock Institute, Department of Welfare, Health, Traceability, Hygiene, 149 rue de Bercy, F-75595 Paris, France \\ †INRA, UMR1300 Biologie Epidémiologie et Analyse de Risques en Santé Animale, F-44307 Nantes, France \\ ILUNAM Université, Oniris, Nantes-Atlantic National College of Veterinary Medicine, Food Science and Engineering, UMR BioEpAR, \\ F-44307 Nantes, France
}

\section{ABSTRACT}

The objective of this study was to estimate the association between digital dermatitis (DD) lesions and test-day milk yield (TDY) in dairy cows, taking into account the severity of the lesions. Data were collected for 6 mo on 47 French dairy farms endemically affected by DD and involved in a clinical trial aiming to assess the effectiveness of collective treatments against DD. The hind feet of all lactating cows were scored for DD by 14 trained investigators on a monthly basis using a 4-point M-stage scoring system (M0 to M4, M standing for Mortellaro). The DD status was defined in 3 categories at the animal level: no DD [scores of M0 and (or) M4 on both feet], moderate case (score of M1 on 1 or both feet and no M2 score), and severe case (score of M2 on 1 or both feet). All monthly TDY in the lactation were collected. The final complete data set included 7,599 TDY of 1,782 Holstein cows from 41 herds. The effect of DD lesions on the following TDY (i.e., within $30 \mathrm{~d}$ after detection of a DD lesion) was analyzed separately for primiparous and multiparous cows, using mixed-models ANOVA, with TDY as repeated measures. During the trial, $38 \%$ of the primiparous and $41 \%$ of the multiparous cows were observed at least once with a DD lesion (moderate or severe case), the cows being observed with a DD lesion, on average, for 2 consecutive visits. Milk yield decreased significantly for cows diagnosed with a DD lesion. Primiparous cows produced, on average, $0.63 \mathrm{~kg} / \mathrm{d}$ less when DD was moderate and 0.50 $\mathrm{kg} / \mathrm{d}$ less when the disease was severe, compared with unaffected cows. Multiparous cows produced, on average, $0.50 \mathrm{~kg} / \mathrm{d}$ less when DD was moderate and 0.75 $\mathrm{kg} / \mathrm{d}$ less when the disease was severe, compared with unaffected cows. These results confirm that DD lesions have a significant effect on the milk yield of dairy cows, including when animals are rigorously treated. Milk

Received July 12, 2012.

Accepted December 22, 2012.

${ }^{1}$ Corresponding author: raphael.guatteo@oniris-nantes.fr yield losses, thus, should be considered when evaluating the costs and benefits of DD control programs.

Key words: dairy cow, digital dermatitis, milk yield, milk loss

\section{INTRODUCTION}

In response to studies reporting a lack of detection and care of lameness, experts from the European Food Safety Authority (Parma, Italy) recently recommended the implementation of programs to prevent lameness as a priority measure to improve dairy cow welfare (Algers et al., 2009). However, as in France no funding or quality label is available to offset the cost of such programs, their implementation often depends solely on the willingness of farmers. Although farmers are aware of the pain associated with lameness and seek to reduce its frequency (Leach et al., 2010b), they only will implement prevention program measures if these are compatible with their daily work schedule and offer some kind of economic benefit (Leach et al., 2010a). The latter depends on the balance between the losses caused by lameness, the costs of prevention measures, and ultimately the gain expected from their implementation (McInerney et al., 1992).

These issues are crucial for the prevention of digital dermatitis (DD), one of the most frequent foot disorders in dairy herds in Europe and North America (Holzhauer et al., 2006; Capion et al., 2008; Cramer et al., 2009b). Indeed, although measures exist to prevent DD, such as the regular application of disinfectants through footbaths, these are applied rarely or irregularly on French dairy cattle farms (Relun, 2011). One reason for this poor observance of treatments is the cost of their application, both in terms of the cost of labor required and that of the treatment product, coupled with farmers' lack of perception of a gain that could result from controlling DD on their farms.

Unfortunately, the detrimental effect of DD on cow performance remains uncertain. Hernandez et al. (2001) and de Jesús Argáez-Rodriguez et al. (1997) found that 
DD had a negative effect on reproductive performance, increasing the days open from 30 to $40 \mathrm{~d}$. Cramer et al. (2009a) found no supplementary risk of culling when a cow had a DD lesion during her last lactation. The effect of DD on milk yield is the most controversial. Some authors found no loss in milk yield related to DD (Ettema et al., 2007; Amory et al., 2008), whereas others found evidence of low but significant losses (de Jesús Argáez-Rodriguez et al., 1997; Warnick et al., 2001; Hernandez et al., 2002; Green et al., 2010). Finally, one study even found high and significant losses (Pavlenko et al., 2011).

One of the difficulties in estimating the effect of DD on milk yield is to obtain accurate data. Several studies relied on DD cases reported by farm personnel (Warnick et al., 2001; Amory et al., 2008), the cases being sometimes confirmed by a veterinarian, a claw trimmer or a researcher (de Jesús Argáez-Rodriguez et al., 1997; Hernandez et al., 2002; Green et al., 2010). A recent study (Relun et al., 2012) found that farm personnel detected less than $30 \%$ of active DD lesions identified by the researchers. Studies based on farmers-reported cases may, thus, result in incorrect classification of DD cases and bias the estimation of the effect of DD on milk yield (Fourichon et al., 1999). The second difficulty is to correctly quantify the effect of DD on milk yield. Different statistical approaches have been used in the literature, which could partly explain conflicting results of the effect of DD on milk yield (Bicalho et al., 2008). The repeated-measures approach is currently preferred to investigate the effect of DD or other diseases on milk yield, but no consensus exists on the best methodology that should be used, and this is likely to depend on the data available (Bicalho et al., 2008). Finally, there is a lack of data that can be used to model the economic impact of DD. One input in such models is the prevalence measured at routine herd claw-trimming sessions (Bruijnis et al., 2010; Ettema et al., 2010). As DD lesions observed at claw-trimming do not necessary cause clinical lameness (Capion et al., 2009; Frankena et al., 2009), a need exists to estimate milk losses due to DD lesions, with or without lameness. As the severity of DD lesions varies between herds (Manske et al., 2002; Somers et al., 2003; Relun et al., 2011), an estimation of the effect of DD based on the recording of DD lesions could be improved by taking into account the severity of DD lesions. The objective of this study was to estimate the association between different severities of DD, based on lesions scored during milking on all lactating cows, and test-day milk yield (TDY) of Holstein cows on French dairy farms where DD was endemic and treated.

\section{MATERIALS AND METHODS}

\section{Study Population}

The data used in this study were drawn from data collected under the framework of a clinical trial aiming to assess the effectiveness of different collective treatment regimens (Relun et al., 2012). This study was conducted from November 2009 to October 2010 on commercial dairy farms in Western France. All of the procedures were carried out under the agreement of the Ethics Committee for Animal Experimentation of Pays de la Loire (CEEA, France). The details regarding the selection of farms and the characteristics of the animals included are available in the article by Relun et al. (2012). Briefly, the farms were selected based on their history of DD ( $>2$ yr endemicity of DD), their milking system (milking parlor: DD scoring location), and their enrollment in the milk-recording scheme. Forty-seven farms had milk yield records for the study period. Most farms $(\mathrm{n}=40)$ were equipped with cubicles and 7 farms housed their dairy cows in straw yards. Five farms were under zero-grazing systems, the others $(\mathrm{n}=42)$ let cows out to pasture in the spring and summer seasons. On average, 70 cows (29 to 129 cows) were milked per farm twice per day. The average milk production was $8,937 \mathrm{~kg}$ over a 305 -d lactation period for Holstein cows (ranging from 5,357 to $12,636 \mathrm{~kg}$ ). During this study, all the farmers had to treat affected cows by applying individual antibiotic (oxytetracycline) topical treatment on DD lesions (M1 or M2, see below for definitions) they had detected (2 applications on washed feet, 2 d apart). In the control regimen, farmers controlled DD only with individual treatments $(\mathrm{n}=15$ herds). In the other regimens, additionally to the individual treatments, the farmers applied a disinfectant solution of copper and zinc chelates on the feet, either by spraying the solution on the hind feet in the milking parlor for 2 d every 2 wk ( $n=12$ herds), or thanks to a split footbath, applied for $2 \mathrm{~d}$ every $15 \mathrm{~d}(\mathrm{n}=11)$ or every 4 wk $(\mathrm{n}=9)$.

\section{Data Collection}

With regard to the study population, readers may refer to the article by Relun et al. (2012) for a detailed description of the data collection. Briefly, the farms were visited 8 times, about every 4 wk, by 14 investigators trained by the first author. During the farm visits, the hind feet of all of the lactating cows were examined in the milking parlor and scored following the method developed by Relun et al. (2011), with a 4-point M-stage scoring system (M standing for 
Mortellaro) adapted from the stages defined by Döpfer et al. (1997). This scoring is well suited to describe the development of DD over time: $\mathbf{M 0}=$ absence of a DD lesion; $\mathbf{M 1}$ = early or intermediate stage, with a small, circumscribed, red to gray epithelial defect of less than $2 \mathrm{~cm}$ in diameter; $\mathbf{M} \mathbf{2}=$ the classical ulcerative (bright red) or granulomatous (red-gray) stage with a diameter $>2 \mathrm{~cm} ; \mathbf{M} 4=$ the late chronic stage characterized by a hyperkeratotic lesion (mostly thickened epithelium), with or without a surface proliferation. The M1 and M2 stages are usually considered as active lesions (i.e., potentially painful and infectious), whereas M4 and M0 are considered as nonpainful and clinically cured lesions (Somers et al., 2003; Capion et al., 2008). Data on the animal's health status was filled in by the farmers in health booklet sheets that were collected by the investigators on each visit. The data on parity, calving dates, and milk yield were obtained from the milk-recording scheme from 2009 and 2010. The TDY were collected on a monthly basis, with fewer records in August, which is a holiday month for milk collectors.

\section{Data Analysis}

Raw data were entered into an Access database (Microsoft Corp., Redmond, WA). They were then transferred into SAS 9.1.3 (SAS Institute Inc., Cary, NC) to build the variables of interest and carry out statistical analyses.

To measure the effect of the severity of DD lesions on TDY, DD status was defined in 3 categories at the animal level, as defined by Frankena et al. (2009): no DD [scores of M0 and (or) M4 on both feet; Somers et al., 2005b], moderate case (score of M1 on 1 or both feet and no M2 score), and severe case (score of M2 on 1 or both feet). As the DD status of animals was not necessarily measured on the test day and DD status could evolve between 2 successive scorings (Nielsen et al., 2012), a selection of data was required to limit ranking bias. A cow was considered as affected by DD (moderately or severely) on a given test day if it has been observed as affected by DD (moderately or severely) within $30 \mathrm{~d}$ preceding the test day. A cow was considered as unaffected by DD on a given test day if it has been observed as unaffected during the 2 preceding visits (to avoid measuring the effect of a previous DD lesion) and during the visit following the test day (to avoid measuring the effect of a DD lesion appeared between DD scoring and the test day). Only cows that had been scored for DD during at least 3 consecutive visits at intervals of less than $45 \mathrm{~d}$ were retained in the analysis (1 farm excluded). Only TDY collected during 340 DIM, and associated with a DD scoring (DD scored within $30 \mathrm{~d}$ preceding the test day), were retained in the analysis. Due to the low numbers of some breeds present, breed could not be included as an adjustment variable and only data from Holstein cows were included in the analysis (2 farms excluded). Last, the data collected by 1 investigator (3 farms) were excluded from the analysis because discrepancies existed between the DD scores given by this investigator and those of other investigators (Relun et al., 2012).

Prior to statistical analyses, observations were checked for unlikely values; data of 1 cow were excluded because of very low milk yield at each test day without underlying reason (no disease; no DD lesion). The relationship between cow characteristics at each test day and DD status was determined using $\chi^{2}$ or Fisher exact tests (PROC FREQ of SAS).

The effect of DD lesions on the following TDY (i.e., within $30 \mathrm{~d}$ after detection of a DD lesion) was analyzed separately for primiparous and multiparous cows, using mixed-models ANOVA, with test-day measurements as repeated measures (PROC MIXED of SAS). Test-day milk yield expressed in kilograms per day was the outcome variable. It was normally distributed. It could vary according to the DD status of the cow on the preceding visit and to numerous covariates known to influence milk production. Two nested random effects at the herd and investigator levels were included in each model to adjust for hierarchical clustering of cows within herds, and herds within investigators. Each model also included a spatial power covariance structure $[\mathrm{SP}(\mathrm{POW})]$ type of correlation matrix based on the length of time between the test day and the previous calving to take into account the correlation between TDY of the same cow over time. The use of the $\mathrm{SP}(\mathrm{POW})$ matrix provided the best model fit with the data, compared with the use of an autoregressive matrix of rank 1, by using the Akaike information criterion (Akaike, 1974).

The statistical models were written as follows:

$$
\operatorname{TDY}_{t i j}=\mu+\sum \beta_{t i j} X_{t i j}+\sum \beta_{i j} X_{i j}+\sum \beta_{j} X_{j}+u_{j k}+v_{k}+\varepsilon_{t i j}
$$

with

$$
\begin{aligned}
& u_{j k} \sim N\left(0, \sigma_{u}^{2}\right), v_{k} \sim N\left(0, \sigma_{v}^{2}\right), \\
& \varepsilon_{t i j}=\left[\varepsilon_{1 i j}, \varepsilon_{2 i j}, \ldots, \varepsilon_{9 i j}\right] \sim N(0, \boldsymbol{\Sigma}),
\end{aligned}
$$

where $\mathrm{TDY}_{t i j}=$ milk yield for cow $i$ belonging to farm $j$ on test day $t, \mu=$ average milk yield after adjusting for covariates, $\beta_{t i j}=$ coefficients for $X_{t i j}, X_{t i j}=$ variables varying between test day, $\beta_{i j}=$ coefficients for $X_{i j}, X_{i j}=$ variables varying between cows, $\beta_{j}=$ coefficients for $X_{j}$, 
$X_{j}=$ variables varying between farms, $u_{j k}=$ random nested effects related to the farm $j$ and the investigator $k, v_{k}=$ random effect related to the investigator $k$, and $\varepsilon_{t i j}=$ residual at test day $t$, the residuals following a normal multidimensional distribution in which the variance-covariance matrix $\boldsymbol{\Sigma}$ depends on the time lag $\mathrm{d}_{\mathrm{t}-(\mathrm{t}-1)}$ between 2 test days (expressed in days). The random effects $u_{j k}$ and $v_{k}$ were assumed to be normally distributed with mean 0 and variance $\sigma_{u}^{2}$ and $\sigma_{v}^{2}$, respectively.

Five factors were included as covariates in both models: month in milk at test day (1 to 12), season of milk yield recording (December to February, March to May, or June to August), presence of disease or veterinarian intervention within the $30 \mathrm{~d}$ preceding the test day (yes or no), access to pasture during the $30 \mathrm{~d}$ preceding the test day (yes or no), and type of housing (cubicle or straw yard). The diseases or veterinary interventions included as potential confounders for milk production were mastitis, lameness other than DD, dystocia, abortion, metabolic disorders, digestive disorders, respiratory disorders, heart disorders, neurological disorders, actinobacillosis (wooden tongue), cesarean, and other surgical interventions. As age at first calving may affect milk yield in first lactation (Losinger and Heinrichs, 1997; Ettema and Santos, 2004), this factor was added as a covariate in the primiparous model with 2 ages at calving categories $(<700 \mathrm{~d}$ and $\geq 700 \mathrm{~d})$. The thresholds of categories were defined following the recommendations of Ettema and Santos (2004). Parity (2, 3, and 4 and over) and milk yield potential (low, moderate, and high) were added as covariates in the multiparous model. The thresholds were defined for each level of milk yield potential by taking the terciles of the preceding 305-d milk production, estimated by the Fleischmann method, for each parity. The associations between explanatory variables were investigated by looking at the correlation coefficients (Spearman's rho) at cow level, using PROC CORR of SAS. If variables were too highly correlated (i.e., if a correlation coefficient $\geq 0.6$ was found), only the variable with the best fit in the model was further included in the analysis, using the Akaike information criterion.

The model selection process involved 2 steps. In the first step, variables were selected using univariable models and retained for multivariable analysis if they significantly influenced the TDY at a threshold of $P \leq$ 0.20 . In the second step, the remaining variables were selected in the multivariable model by backward stepwise selection, with DD status forced into the model until all variables significantly $(P \leq 0.05)$ contributed to the model. The presence of confounders was investigated by checking that the estimates were not changed by more than $20 \%$ when a variable was withdrawn from the model. In the affirmative, the variable was kept in the model. In both steps, 2-way interactions were tested between all main effects remaining in the models, and careful attention was paid to the epidemiologic plausibility of the resulting models. The goodness of fit of the final models was assessed by graphic procedures and by the Kolmogorov-Smirnov test (Massey, 1951), to assess if the distribution of standardized residuals fitted with a standard normal distribution. The KolmogorovSmirnov test was supplemented by a verification of skewness and kurtosis coefficients.

\section{RESULTS}

\section{Descriptive Statistics}

After selection, the data set included 7,599 TDY corresponding to 1,782 cows on 41 farms; 697 cows were primiparous (3,009 TDY), and 1,085 multiparous (4,590 TDY). The daily milk yield during the study period was, on average, $26.0 \mathrm{~kg}$ for primiparous cows (range from 6.7 to $41.7 \mathrm{~kg}$ ) and $30.0 \mathrm{~kg}$ for multiparous cows (range from 3.2 to $66.5 \mathrm{~kg}$ ).

Thirty-eight percent $(\mathrm{n}=266)$ of primiparous and $41 \%(\mathrm{n}=448)$ of multiparous cows were affected at least once by DD during the study period. DD active lesions were observed on average for 2 consecutive visits (range from 1 to 6 visits). One $\%(n=21)$ of cows were observed with recurrent DD lesions. Digital dermatitis active lesions most often occurred on one of the hind feet (Table 1). Digital dermatitis occurred throughout lactation, but the cows appeared to be less often and less severely affected at the end of the lactation (Tables 2 and 3). Digital dermatitis also occurred less often and less severely during the spring season and when cows had access to pasture (Tables 2 and 3). Among primiparous cows, cows were less often and less severely affected when they were $700 \mathrm{~d}$ or older at their first calving (Table 2). Among multiparous cows, cows were less often and less severely affected when they were in parity 4 or more and when they had a medium milk yield potential (Table 3 ).

\section{Effect of DD on Milk Production}

In the first step of analysis (univariable analyses), 4 variables showed a relationship with TDY in the primiparous model: DD status, access to pasture, month in milk, and season of milk-yield recording. In the multiparous model, 8 variables showed a relationship with TDY: DD status, milk yield potential, parity, occurrence of a debilitating disease, access to pasture, type 
Table 1. Number and percent of digital dermatitis (DD) lesions by parity in 1,782 Holstein cows from 41 French dairy herds from December 2009 to August 2010

\begin{tabular}{|c|c|c|c|c|c|}
\hline \multirow[b]{2}{*}{ DD status } & \multirow[b]{2}{*}{ M-stage ${ }^{1}$} & \multicolumn{2}{|c|}{ Primiparous cows } & \multicolumn{2}{|c|}{ Multiparous cows } \\
\hline & & $\begin{array}{c}\text { No. of } \\
\text { occasions }\end{array}$ & $\%$ & $\begin{array}{l}\text { No. of } \\
\text { occasions }\end{array}$ & $\%$ \\
\hline \multirow{3}{*}{ Unaffected $(\mathrm{n}=3,767)$} & M0-M0 & 1,867 & 61.9 & 2,001 & 43.6 \\
\hline & M0-M4 & 262 & 8.7 & 550 & 12.0 \\
\hline & M4-M4 & 337 & 11.2 & 1,216 & 26.5 \\
\hline \multirow[t]{3}{*}{ Moderately affected $(\mathrm{n}=484)$} & M0-M1 & 102 & 3.4 & 165 & 3.6 \\
\hline & M4-M1 & 111 & 3.7 & 232 & 5.1 \\
\hline & M1-M1 & 32 & 1.1 & 87 & 1.9 \\
\hline \multirow[t]{4}{*}{ Severely affected $(\mathrm{n}=339)$} & M0-M2 & 89 & 3.0 & 85 & 1.9 \\
\hline & M4-M2 & 137 & 4.5 & 145 & 3.2 \\
\hline & M1-M2 & 34 & 1.1 & 41 & 0.9 \\
\hline & M2-M2 & 43 & 1.4 & 68 & 1.5 \\
\hline
\end{tabular}

${ }^{1}$ Stages of DD lesions observed on both hind feet, based on the scoring system first described by Döpfer et al. (1997): M0 = no DD lesion; M1 = an early or intermediate stage with a small, circumscribed, red to gray epithelial defect of less than $2 \mathrm{~cm}$ in diameter; $\mathrm{M} 2=$ the classical ulcerative (bright red) or granulomatous (red-gray) stage with a diameter $>2 \mathrm{~cm} ; \mathrm{M} 4=$ the late chronic stage characterized by a hyperkeratotic lesion (mostly thickened epithelium), with or without a surface proliferation.

Table 2. Relationship between cow characteristics, month of milk yield recording, and digital dermatitis (DD) status for 697 primiparous Holstein cows from 41 French dairy herds from December 2009 to August 2010

\begin{tabular}{|c|c|c|c|c|c|}
\hline \multirow[b]{2}{*}{ Variable $(\%)$} & \multirow[b]{2}{*}{$\begin{array}{c}\text { No. of } \\
\text { observations }\end{array}$} & \multicolumn{3}{|c|}{ DD status ${ }^{1}$} & \multirow[b]{2}{*}{$P$-value } \\
\hline & & $\begin{array}{l}\text { Unaffected } \\
(\mathrm{n}=2,461)\end{array}$ & $\begin{array}{l}\text { Moderate } \\
(\mathrm{n}=245)\end{array}$ & $\begin{array}{c}\text { Severe } \\
(\mathrm{n}=303)\end{array}$ & \\
\hline Month in milk & & & & & 0.05 \\
\hline 2 & 100 & 87.0 & 5.0 & 8.0 & \\
\hline 3 & 204 & 78.4 & 8.3 & 13.3 & \\
\hline 4 & 296 & 79.1 & 8.4 & 12.5 & \\
\hline 5 & 378 & 70.7 & 5.8 & 13.5 & \\
\hline 6 & 422 & 81.1 & 7.8 & 11.1 & \\
\hline 7 & 413 & 84.8 & 7.0 & 8.2 & \\
\hline 8 & 426 & 82.4 & 8.9 & 8.7 & \\
\hline 9 & 334 & 83.2 & 7.8 & 9.0 & \\
\hline 10 & 245 & 80.8 & 9.8 & 9.4 & \\
\hline 11 & 146 & 82.2 & 13.0 & 4.8 & \\
\hline 12 & 45 & 80.0 & 15.6 & 4.4 & \\
\hline Age at first calving & & & & & $<10^{-4}$ \\
\hline$<700 \mathrm{~d}$ & 107 & 63.6 & 17.8 & 18.7 & \\
\hline$\geq 700 \mathrm{~d}$ & 2,902 & 82.5 & 7.8 & 9.7 & \\
\hline Debilitating disease $\mathrm{e}^{2,3}$ & & & & & 0.14 \\
\hline No & 2,842 & 82.2 & 8.0 & 9.8 & \\
\hline Yes & 168 & 76.2 & 10.1 & 13.7 & \\
\hline Access to pastures $^{2}$ & & & & & $<10^{-4}$ \\
\hline No & 2,122 & 78.0 & 9.4 & 12.7 & \\
\hline Yes & 887 & 91.0 & 5.2 & 3.8 & \\
\hline Type of housing & & & & & 0.004 \\
\hline Straw yards & 293 & 88.9 & 5.0 & 6.0 & \\
\hline Cubicles & 2,716 & 81.0 & 8.5 & 10.5 & \\
\hline Season of milk yield recording & & & & & 0.71 \\
\hline December to February & 966 & 80.8 & 8.1 & 11.1 & \\
\hline March to May & 1,628 & 82.4 & 8.2 & 9.4 & \\
\hline June to August & 415 & 82.0 & 7.9 & 10.1 & \\
\hline
\end{tabular}

${ }^{1}$ Severity of DD within $30 \mathrm{~d}$ preceding the milk yield-recording date: unaffected $=\mathrm{M} 0$ or M4 on the 2 hind feet; moderate = M1 on 1 or both hind feet; severe = M2 on 1 or both hind feet, where M0 = no DD lesion; $\mathrm{M} 1$ = an early or intermediate stage with a small, circumscribed, red to gray epithelial defect of less than $2 \mathrm{~cm}$ in diameter; $\mathrm{M} 2$ = the classical ulcerative (bright red) or granulomatous (red-gray) stage with a diameter $>2$ $\mathrm{cm} ; \mathrm{M} 4=$ the late chronic stage characterized by a hyperkeratotic lesion (mostly thickened epithelium), with or without a surface proliferation.

${ }^{2}$ Within the $30 \mathrm{~d}$ preceding the milk yield-recording date.

${ }^{3}$ Mastitis, lameness other than DD, cesarean, dystocia, abortion, metabolic disorders, digestive disorders, respiratory disorders, cardiac disorders, neurological disorders, surgical intervention, wooden tongue, or vaccination. 
Table 3. Relationship between cow characteristics, month of milk yield recording, and digital dermatitis (DD) status for 1,085 multiparous Holstein cows from 41 French dairy herds from December 2009 to August 2010

\begin{tabular}{|c|c|c|c|c|c|}
\hline \multirow[b]{2}{*}{ Variable $(\%)$} & \multirow[b]{2}{*}{$\begin{array}{c}\text { No. of } \\
\text { observations }\end{array}$} & \multicolumn{3}{|c|}{ DD status ${ }^{1}$} & \multirow[b]{2}{*}{$P$-value } \\
\hline & & $\begin{array}{c}\text { Unaffected } \\
(\mathrm{n}=3,767)\end{array}$ & $\begin{array}{l}\text { Moderate } \\
(\mathrm{n}=484)\end{array}$ & $\begin{array}{c}\text { Severe } \\
(\mathrm{n}=339)\end{array}$ & \\
\hline Parity & & & & & 0.0005 \\
\hline 2 & 1,952 & 80.3 & 11.1 & 8.6 & \\
\hline 3 & 1.255 & 81.0 & 10.9 & 8.1 & \\
\hline$\geq 4$ & 1,383 & 85.5 & 9.4 & 5.1 & \\
\hline Month in milk & & & & & 0.66 \\
\hline 1 & 9 & 77.8 & 22.2 & 0 & \\
\hline 2 & 185 & 81.1 & 10.8 & 8.1 & \\
\hline 3 & 359 & 79.9 & 9.8 & 10.3 & \\
\hline 4 & 500 & 82.2 & 11.0 & 6.8 & \\
\hline 5 & 611 & 82.0 & 10.1 & 7.9 & \\
\hline 6 & 677 & 84.3 & 9.3 & 6.4 & \\
\hline 7 & 652 & 82.4 & 10.6 & 7.0 & \\
\hline 8 & 576 & 82.4 & 10.8 & 6.8 & \\
\hline 9 & 480 & 81.9 & 10.2 & 7.9 & \\
\hline 10 & 306 & 90.4 & 10.8 & 8.8 & \\
\hline 11 & 186 & 81.7 & 12.9 & 5.4 & \\
\hline 12 & 49 & 75.5 & 20.4 & 4.1 & \\
\hline Milk yield potential $^{2}$ & & & & & $<10^{-4}$ \\
\hline Low & 1,514 & 78.7 & 12.8 & 8.6 & \\
\hline Medium & 1,525 & 85.2 & 9.6 & 5.2 & \\
\hline High & 1,551 & 82.3 & 9.3 & 8.4 & \\
\hline Debilitating disease ${ }^{3,4}$ & & & & & 0.46 \\
\hline No & 4,272 & 82.2 & 10.5 & 7.3 & \\
\hline Yes & 318 & 80.2 & 10.7 & 9.1 & \\
\hline Access to pastures ${ }^{4}$ & & & & & $<10^{-4}$ \\
\hline No & 3,130 & 80.3 & 11.1 & 8.7 & \\
\hline Yes & 1,460 & 86.0 & 9.5 & 4.6 & \\
\hline Type of housing & & & & & 0.31 \\
\hline Straw yards & 486 & 84.2 & 10.1 & 5.8 & \\
\hline Cubicles & 4,104 & 81.8 & 10.6 & 7.6 & \\
\hline Season of milk yield recording & & & & & 0.43 \\
\hline December to February & 1,479 & 80.7 & 11.7 & 7.6 & \\
\hline March to May & 2,453 & 82.9 & 9.9 & 7.2 & \\
\hline June to August & 658 & 81.9 & 10.5 & 7.6 & \\
\hline
\end{tabular}

${ }^{1}$ Severity of DD within $30 \mathrm{~d}$ preceding the milk yield recording date: unaffected $=\mathrm{M} 0$ or M4 on the 2 hind feet; moderate $=\mathrm{M} 1$ on 1 or both hind feet; severe $=\mathrm{M} 2$ on 1 or both hind feet, where M0 = no DD lesion; $\mathrm{M} 1$ = an early or intermediate stage with a small, circumscribed, red to gray epithelial defect of less than $2 \mathrm{~cm}$ in diameter; M2 = the classical ulcerative (bright red) or granulomatous (red-gray) stage with a diameter $>2$ $\mathrm{cm} ; \mathrm{M} 4=$ the late chronic stage characterized by a hyperkeratotic lesion (mostly thickened epithelium), with or without a surface proliferation.

${ }^{2}$ Based on milk-production level during the preceding lactation, the thresholds of categories defined by terciles of their 305-d lactation, for each parity.

${ }^{3}$ Within the $30 \mathrm{~d}$ preceding the milk yield-recording date.

${ }^{4}$ Mastitis, lameness other than DD, cesarean, dystocia, abortion, metabolic disorders, digestive disorders, respiratory disorders, cardiac disorders, neurological disorders, surgical intervention, wooden tongue, or vaccination.

of housing, month in milk, and season of milk-yield recording. After the second step, 3 variables remained in the primiparous model (Table 4) and 7 variables in the multiparous model (Table 5). The only significant interaction in both steps was between the variables month in milk and parity in the multiparous model.

For the final primiparous model, the baseline for comparison was a cow in the second month of milk, without a detected DD lesion, and for which milk yield had been recorded during the winter season (Table 4). Cows with a DD lesion produced, on average, $0.63 \mathrm{~kg} / \mathrm{d}$ (95\% CI: 0.16, 1.12) less when the disease was moder- ate and $0.50 \mathrm{~kg} / \mathrm{d}(95 \% \mathrm{CI}:-0.01,1.00)$ less when the disease was severe. The production between moderately and severely affected primiparous cows did not differ $(P$ $=0.92$ ). When the moderate and severe DD statuses were merged, a cow produced, on average, $0.57 \mathrm{~kg} / \mathrm{d}$ (95 CI: 0.18, 0.96) less. Significant variations between herds were observed $\left(P<10^{-4}\right.$; variance component of the herd frailty effect: $15.00 \mathrm{~kg} / \mathrm{d}$; SE: $0.91 \mathrm{~kg} / \mathrm{d}$ ), but not between investigators.

For the final multiparous model, the baseline for comparison was a cow of parity 2 , in the second month of milk, without a detected DD lesion, without any de- 
Table 4. Association of digital dermatitis (DD) status and cow-level confounders with test-day milk yield (TDY) in the final mixed ANOVA model of 3,099 observations on 697 primiparous Holstein cows from 41 French dairy herds from December 2009 to August 2010

\begin{tabular}{|c|c|c|c|c|}
\hline Variable & $\begin{array}{c}\text { No. of } \\
\text { observations }\end{array}$ & $\begin{array}{l}\text { Average effect } \\
\qquad(\mathrm{kg} / \mathrm{d})\end{array}$ & $\begin{array}{l}\text { Lower } \\
95 \% \text { CI }\end{array}$ & $\begin{array}{l}\text { Upper } \\
95 \% \text { CI }\end{array}$ \\
\hline Intercept & 3,009 & 28.08 & 27.44 & 28.88 \\
\hline \multicolumn{5}{|l|}{ DD status ${ }^{1}$} \\
\hline Unaffected & 2,461 & Reference & — & — \\
\hline Moderately affected & 245 & -0.63 & -1.12 & -0.16 \\
\hline Severely affected & 307 & -0.50 & -1.00 & 0.01 \\
\hline \multicolumn{5}{|l|}{ Month in milk } \\
\hline 2 & 100 & Reference & - & - \\
\hline 3 & 204 & -0.37 & -1.07 & 0.32 \\
\hline 4 & 296 & -0.64 & -1.32 & 0.03 \\
\hline 5 & 378 & -1.14 & -1.83 & -0.45 \\
\hline 6 & 422 & -1.59 & -2.30 & -0.87 \\
\hline 7 & 413 & -2.13 & -2.89 & -1.37 \\
\hline 8 & 426 & -2.34 & -3.15 & -1.54 \\
\hline 9 & 334 & -3.25 & -4.11 & -2.39 \\
\hline 10 & 245 & -3.88 & -4.82 & -2.94 \\
\hline 11 & 146 & -4.87 & -5.89 & -3.84 \\
\hline 12 & 45 & -4.88 & -6.19 & -3.56 \\
\hline \multicolumn{5}{|c|}{ Season of milk yield recording } \\
\hline December to February & 966 & Reference & - & - \\
\hline March to May & 1,628 & 0.15 & -0.16 & 0.47 \\
\hline June to August & 415 & -0.71 & -1.25 & -0.18 \\
\hline
\end{tabular}

${ }^{1}$ Severity of DD within $30 \mathrm{~d}$ preceding the milk yield-recording date: unaffected $=\mathrm{M} 0$ or M4 on the 2 hind feet; moderate $=\mathrm{M} 1$ on 1 or both hind feet; severe $=\mathrm{M} 2$ on 1 or both hind feet, where M0 = no DD lesion; $\mathrm{M} 1=$ an early or intermediate stage with a small, circumscribed, red to gray epithelial defect of less than $2 \mathrm{~cm}$ in diameter; $\mathrm{M} 2$ = the classical ulcerative (bright red) or granulomatous (red-gray) stage with a diameter $>2$ $\mathrm{cm} ; \mathrm{M} 4=$ the late chronic stage characterized by a hyperkeratotic lesion (mostly thickened epithelium), with or without a surface proliferation.

bilitating disease, with the lowest milk yield potential, that was housed in cubicles, and for which milk yield had been recorded during the winter season (Table 5). Cows with a DD lesion produced, on average, $0.50 \mathrm{~kg} / \mathrm{d}$ (95\% CI: 0.09, 0.92) less when the disease was moderate and $0.75 \mathrm{~kg} / \mathrm{d}(95 \% \mathrm{CI}: 0.21,1.29)$ less when the disease was severe. The production between moderately and severely affected multiparous cows did not differ $(P$ $=0.78)$. When the moderate and severe DD statuses were merged, a cow produced, on average, $0.57 \mathrm{~kg} / \mathrm{d}$ (95 CI: $0.21,0.94)$ less. Cows affected by a debilitating disease produced, on average, $1.01 \mathrm{~kg} / \mathrm{d}$ (95 CI: 0.57, 1.44) less than unaffected cows. Multiparous cows also produced significantly less milk when they were housed in cubicles rather than straw yards. Significant variations were observed between herds $\left(P<10^{-4}\right.$; variance: $15.51 \mathrm{~kg} / \mathrm{d}$; SE: $0.85 \mathrm{~kg} / \mathrm{d})$ and between investigators $\left(P<10^{-4}\right.$; variance: $0.60 \mathrm{~kg} / \mathrm{d}$; SE: $\left.0.02 \mathrm{~kg} / \mathrm{d}\right)$.

\section{Goodness of Fit of the Models}

The standardized residuals followed a standard normal distribution both for the primiparous cow model (Kolmogorov-Smirnov: $P>0.15$; skewness $=-0.26$; kurtosis $=0.49)$ and for the multiparous cow model (Kolmogorov-Smirnov: $P<0.01$; skewness $=-0.28$; kurtosis $=1.06)$. The distributions of the standardized residuals for the 2 models fitted graphically with a standard normal distribution.

\section{DISCUSSION}

The originality of this study was to investigate the association between DD lesions, taking into account their severity, and test-day milk yield of Holstein cows, the lesions being scored on all lactating cows from commercial dairy herds by trained investigators. Results showed that DD lesions had a slight, but significant effect on the milk yield within $30 \mathrm{~d}$ following their detection, whatever the severity of the lesions. These results were obtained using linear mixed models with repeated measures, adjusted on milk yield potential for multiparous cows, as recommended by Bicalho et al. (2008). Some recent studies used another approach to quantify the effect of DD on milk yield [i.e., a diseaseindexing methodology that combines a binary variable DD (yes or no) and the time before and after the diagnosis of DD (Warnick et al., 2001; Amory et al., 2008; Green et al., 2010]. In the present study, the severity of the lesions could change over time (data not shown), DD status of animals was not necessarily measured on the test day, and measures were available at monthly 
Table 5. Association of digital dermatitis (DD) status and cow-level confounders with test-day milk yield (TDY) in the final mixed ANOVA model of 4,590 observations on 1,085 multiparous Holstein cows from 41 French dairy herds from December 2009 to August 2010

\begin{tabular}{|c|c|c|c|c|}
\hline Variable & $\begin{array}{c}\text { No. of } \\
\text { observations }\end{array}$ & $\begin{array}{l}\text { Average effect }{ }^{1} \\
(\mathrm{~kg} / \mathrm{d})\end{array}$ & $\begin{array}{l}\text { Lower } \\
95 \% \text { CI }\end{array}$ & $\begin{array}{l}\text { Upper } \\
95 \% \text { CI }\end{array}$ \\
\hline Intercept & 4,590 & 33.46 & 32.43 & 34.49 \\
\hline \multicolumn{5}{|l|}{ DD status ${ }^{2}$} \\
\hline Unaffected & 3,767 & Reference & - & - \\
\hline Moderately affected & 484 & -0.50 & -0.92 & -0.09 \\
\hline Severely affected & 339 & -0.75 & -1.29 & -0.21 \\
\hline \multicolumn{5}{|l|}{ Parity } \\
\hline 2 & 1,952 & Reference & - & - \\
\hline 3 & 1,255 & 3.23 & 1.79 & 4.66 \\
\hline$\geq 4$ & 1,383 & 2.25 & 0.83 & 3.68 \\
\hline \multicolumn{5}{|l|}{ Month in milk } \\
\hline 1 & 9 & -0.57 & -3.74 & 2.60 \\
\hline 2 & 185 & Reference & - & - \\
\hline 3 & 359 & -2.66 & -3.67 & -1.66 \\
\hline 4 & 500 & -4.48 & -5.47 & -3.50 \\
\hline 5 & 611 & -5.47 & -6.45 & -4.50 \\
\hline 6 & 677 & -6.79 & -7.79 & -5.80 \\
\hline 7 & 652 & -7.53 & -8.56 & -6.50 \\
\hline 8 & 576 & -8.71 & -9.79 & -7.63 \\
\hline 9 & 480 & -10.22 & -11.35 & -9.09 \\
\hline 10 & 306 & -11.76 & -12.98 & -10.53 \\
\hline 11 & 186 & -13.34 & -14.71 & -11.97 \\
\hline 12 & 49 & -14.49 & -16.56 & -12.41 \\
\hline \multicolumn{5}{|l|}{ Milk yield potential $^{3}$} \\
\hline Low & 1,514 & Reference & - & - \\
\hline Medium & 1,525 & 2.58 & 1.94 & 3.23 \\
\hline High & 1,551 & 5.55 & 4.91 & 6.18 \\
\hline \multicolumn{5}{|l|}{ Debilitating disease $\mathrm{e}^{4,5}$} \\
\hline No & 4,272 & Reference & - & - \\
\hline Yes & 318 & -1.01 & -1.44 & -0.57 \\
\hline \multicolumn{5}{|l|}{ Type of housing } \\
\hline Straw yards & 486 & 1.79 & 0.89 & 2.69 \\
\hline Cubicles & 4,104 & Reference & - & - \\
\hline \multicolumn{5}{|c|}{ Season of milk yield recording } \\
\hline December to February & 1,479 & 0.77 & 0.46 & 1.08 \\
\hline March to May & 2,453 & Reference & - & - \\
\hline June to August & 658 & -0.32 & -0.84 & 0.20 \\
\hline
\end{tabular}

${ }^{1}$ Controlling for month in milk $\times$ parity interaction.

${ }^{2}$ Severity of DD within $30 \mathrm{~d}$ preceding the milk yield-recording date: unaffected $=\mathrm{M} 0$ or M4 on the 2 hind feet; moderate = M1 on 1 or both hind feet; severe = M2 on 1 or both hind feet, where M0 = no DD lesion; $\mathrm{M} 1=$ an early or intermediate stage with a small, circumscribed, red to gray epithelial defect of less than $2 \mathrm{~cm}$ in diameter; $\mathrm{M} 2$ = the classical ulcerative (bright red) or granulomatous (red-gray) stage with a diameter $>2$ $\mathrm{cm} ; \mathrm{M} 4=$ the late chronic stage characterized by a hyperkeratotic lesion (mostly thickened epithelium), with or without a surface proliferation.

${ }^{3}$ Based on milk production level during the preceding lactation, the thresholds of categories defined by terciles of their 305-d lactation, for each parity.

${ }^{4}$ Within the $30 \mathrm{~d}$ preceding the milk yield-recording date.

${ }^{5}$ Mastitis, lameness other than DD, cesarean, dystocia, abortion, metabolic disorders, digestive disorders, respiratory disorders, cardiac disorders, neurological disorders, surgical intervention, wooden tongue, or vaccination.

intervals. The disease-indexing methodology was, thus, not appropriate to study such an evolutive disease and to differentiate the effect of different severities of DD lesions on the milk yield.

In the present study, the reference was defined as a cow with a hyperkeratotic lesion (M4) or no DD lesion (M0) on both hind feet. Some authors have suggested that, as Treponema had been detected by PCR in tissue samples, M4 lesions should be considered as potentially infectious lesions (Döpfer et al., 2012). This is important when considering the dynamics of the disease. However, when one is interested about the clinical or production effect of DD, hyperkeratotic lesions are usually considered as nonpainful and clinically cured lesions (Read and Walker, 1998; Green et al., 2010). Indeed, most prevalence studies consider that only cows observed with erosive (M1), ulcerative, or granulomatous (M2) lesions are affected by DD (Somers et al., 2003; Holzhauer et al., 2006; Capion et al., 2008). Including cows observed with M4 lesions in the unaffected category 
will, thus, provide estimates that can be used to model the economic impact of the disease. When M4 lesions were included as potentially active DD lesions (data not shown), the result was an underestimation of the effect of DD lesions on milk yield [loss of $0.25 \mathrm{~kg} / \mathrm{d}(95$ CI: $-0.25,0.76)$ for primiparous cows and loss of 0.08 $\mathrm{kg} / \mathrm{d}(95 \mathrm{CI}:-0.46,0.61)]$ for multiparous cows with a DD lesion compared with cows scored M0 on both feet).

Even if the cows were submitted to different DD treatments, these treatments were not included as covariates in the models. Indeed, DD treatments were linked with the DD lesions observed, and treatments could not directly influence milk yield. Including DD treatments as a covariate may, thus, create overmatching, which would result in an underestimation of the effect of DD lesions (Dohoo et al., 2003).

Results of this study indicate that cows observed with a DD lesion produced, on average, $0.6 \mathrm{~kg} / \mathrm{d}$ less than unaffected cows, whatever the severity of the DD lesion (Tables 4 and 5). These results are consistent with those estimated in previous studies, notably those that did not select cases on the basis of the observation of lameness. Warnick et al. (2001) estimated average losses of $0.3 \mathrm{~kg} / \mathrm{d}$ when the diagnosis of DD was based on lesions observed at monthly claw trimmings, and 1.2 $\mathrm{kg} / \mathrm{d}$ when these lesions were observed only on lame cows detected by the farmer. Ettema et al. (2007) found that cows with a medium or a high milk yield index and diagnosed with a DD lesion before 101 DIM at claw trimming produced, on average, 1.2 and $0.8 \mathrm{~kg} / \mathrm{d}$ less of ECM for primiparous and multiparous cows, respectively. Only Pavlenko et al. (2011) estimated significant losses with an average loss of $5.5 \mathrm{~kg} / \mathrm{d}$ of ECM 2 to 6 wk after the diagnosis of a DD lesion, but their results are based on a small sample (10 cases and 10 controls) and most of the cows were affected by severe DD lesions.

The current study did not enable a difference in effect of an active DD lesion on milk yield related to the severity of the DD lesion to be demonstrated (Tables 4 and 5). The different degrees of DD lesion severity were modeled on those defined by Frankena et al. (2009). In that study, the authors observed that $40 \%$ of cows were lame when DD was at a severe stage compared with $26 \%$ when the lesion was moderate. Several factors may explain why no significant difference was highlighted in our study. First, to monitor a large number of farms, the scoring method used was reliable enough to differentiate feet affected with an active lesion and those not affected or affected with inactive lesions, but was less precise in relation to differentiating M1 lesions from M2 lesions (Relun et al., 2011). A certain ranking bias exists, therefore, between M1 and M2 lesions that could have limited the demonstration of a difference in effect. Second, even if lesions scored M1 often are less painful than those scored M2 (Holzhauer et al., 2008), the pain also depends on the location of the lesions, with lesions being more painful when located in the interdigital space than on the coronary band or under the dew claws (Hernandez and Shearer, 2000); M1 lesions are located essentially in the interdigital spaces, whereas M2 lesions can appear in other locations (Holzhauer et al., 2008). It may, therefore, be interesting to consider the anatomic location of lesions to better adjust estimations.

The effect of an active DD lesion on milk yield was quite similar for primiparous and multiparous cows (Tables 4 and 5). The lack of significance for moderate DD cases in the primiparous model is probably due to fewer observations, and results were significant when both statuses (moderate and severe) were merged. However, one must note that the estimation probably is more imprecise among primiparous cows than multiparous cows, as the model could not be adjusted for the milk yield potential of primiparous cows. Among multiparous cows, the model was adjusted to the level of the 305-d milk production of the preceding lactation. However, it is possible that cows infected during the study also were infected during their previous lactation.

Most of the other factors identified as significantly affecting milk yield in this study (Tables 4 and 5) are similar to those described previously, notably stage of lactation, parity, and month of milk-yield recording (Warnick et al., 2001; Green et al., 2002; Hernandez et al., 2002). As debilitating diseases were not differentiated according to type of disease in the current study, it is difficult to compare the results obtained with those of studies that focused specifically on the effect of diseases on milk yield. The aggregation of diseases into a single category, including mastitis and milk fever, under the same title as digestive disorders and vaccination, probably underestimated the impact of diseases reputed to have a strong effect on milk yield, such as mastitis and milk fever (Fourichon et al., 1999; Rajala-Schultz et al., 1999; Bareille et al., 2003). However, the differentiation of diseases into several categories would have led us to divide the sample into groups too small for analysis.

The variance of the herd random effect was quite high in both models. This suggests that several unobserved factors related to herd management (e.g., genetic selection or food management) may have affected the milk yield. Conversely, the variance of the investigator random effect was small, suggesting that DD scoring was repeatable between investigators.

One of the biases often put forward as limiting milk yield estimations is that of anticipated culling of animals due to the disease studied (Beaudeau et al., 1995; 
Fourichon et al., 1999). In such a case, the affected animals often have lower parity and shorter lactations, underestimating the effect of the disease at the end of lactation and for high lactation ranks. It is possible that the estimations in the present study presented this bias, the cows with a lactation rank higher than 3 being less affected by DD, and in a less severe manner, than cows with a lower lactation rank. This difference already has been observed in previous studies (Wells et al., 1999; Somers et al., 2005a; Holzhauer et al., 2006). The authors also hypothesized that although immunity against DD is known to provide little protection, it could become stronger with each lactation, thereby diminishing the susceptibility of older animals. With regard to a potential bias related to reduced lactation duration following anticipated culling, it is probably low for this study because the reasons for culling were recorded by farmers and only 2 cows were culled due to DD. Some cows infected with DD may, however, have dried off earlier without farmers culling them in response.

Although this study allowed a significant reduction in milk yield associated with an active DD lesion to be highlighted, this reduction remains less than the losses estimated for noninfectious foot lesions such as sole ulcers and white line disease. Short-term losses associated with a sole ulcer effectively were estimated to be about $2 \mathrm{~kg} / \mathrm{d}$ in previous studies (Warnick et al., 2001; Amory et al., 2008; Green et al., 2010), and those associated with white line disease to be about $1.5 \mathrm{~kg} / \mathrm{d}$ (Amory et al., 2008). However, one must remember that the estimation of the effect of DD in our study probably underestimated the real impact of the disease. The cows in our study had to be individually treated for $\mathrm{DD}$, and most farmers applied additionally a collective topical disinfectant on the feet regularly every $15 \mathrm{~d}$ or every $4 \mathrm{wk}$. These frequencies of treatment and their regular application over 6 mo represented more rigorous treatments than those practiced by many farmers in France (Relun, 2011). Untreated DD lesions may, therefore, be associated with great effect on milk yield. Furthermore, although the effect of DD was less than other foot lesions at the level of a TDY, one must not forget that DD often is observed recurrently in the same animal and it affects a fairly important proportion of animals within dairy cattle herds. Digital dermatitis is, therefore, probably one of the foot disorders with the greatest economic impact on cattle dairy farms. The results of this study could be used to estimate the economic impact of the disease at the farm level. In the long run, the results could enable an evaluation of the costs and benefits of implementing DD prevention programs. Although a simple economic argument is insufficient to change habits (Greiner et al., 2009), this argument nevertheless is important to justify the implementation of these programs by farmers (Leach et al., 2010b).

\section{CONCLUSIONS}

The results of this study indicate that DD lesions were associated with a slight but significant decrease in the milk production within $30 \mathrm{~d}$ following their detection, in spite of rigorous treatment of the dairy herds. The decrease was not largest when the lesion was more severe. The estimated losses in milk production associated with DD lesions in this study could be used in models to estimate the economic impact of this disease at the farm level. This could, in turn, provide convincing arguments to encourage farmers to implement DDprevention programs on their farms.

\section{ACKNOWLEDGMENTS}

The authors thank everyone who invested themselves in this project, the farmers for their hospitality, the veterinarians and technicians of the Groupements de Défense Sanitaires and the Groupements Techniques Vétérinaires (Brittany and the Loire region, France) and veterinarian students at Oniris (Nantes, France) who monitored the farms, as well as the technicians from the UMR BioEpAR (Oniris-INRA, Nantes, France) for data entry.

\section{REFERENCES}

Akaike, H. 1974. A new look at the statistical model identification IEEE Trans. Automat. Contr. 19:716-723.

Algers, B., H. J. Blokhuis, A. Botner, D. M. Broom, P. Costa, M. Domingo, M. Greiner, J. Hartung, F. Koenen, C. Müller-Graf, M. Raj, D. B. Morton, A. Osterhaus, D. U. Pfeiffer, R. Roberts, M. Sanaa, M. Salman, J. M. Sharp, P. Vannier, and M. Wierup. 2009. Scientific opinion on welfare of dairy cows in relation to leg and locomotion problems based on a risk assessment with special reference to the impact of housing, feeding, management and genetic selection. EFSA J. 1142:1-57.

Amory, J. R., Z. E. Barker, J. L. Wright, S. A. Mason, R. W. Blowey, and L. E. Green. 2008. Associations between sole ulcer, white line disease and digital dermatitis and the milk yield of 1824 dairy cows on 30 dairy cow farms in England and Wales from February 2003-November 2004. Prev. Vet. Med. 83:381-391.

Bareille, N., F. Beaudeau, S. Billon, A. Robert, and P. Faverdin. 2003. Effects of health disorders on feed intake and milk production in dairy cows. Livest. Prod. Sci. 83:53-62.

Beaudeau, F., V. Ducrocq, C. Fourichon, and H. Seegers. 1995. Effect of disease on length of productive life of French Holstein dairy cows assessed by survival analysis. J. Dairy Sci. 78:103-117.

Bicalho, R. C., L. D. Warnick, and C. L. Guard. 2008. Strategies to analyze milk losses caused by diseases with potential incidence throughout the lactation: A lameness example. J. Dairy Sci. 91:2653-2661.

Bruijnis, M. R. N., H. Hogeveen, and E. N. Stassen. 2010. Assessing economic consequences of foot disorders in dairy cattle using a dynamic stochastic simulation model. J. Dairy Sci. 93:2419-2432.

Capion, N., S. M. Thamsborg, and C. Enevoldsen. 2008. Prevalence of foot lesions in Danish Holstein cows. Vet. Rec. 163:80-85. 
Capion, N., S. M. Thamsborg, and C. Enevoldsen. 2009. Prevalence and severity of foot lesions in Danish Holstein heifers through first lactation. Vet. J. 182:50-58.

Cramer, G., K. D. Lissemore, C. L. Guard, K. E. Leslie, and D. F. Kelton. 2009a. The association between foot lesions and culling risk in Ontario Holstein cows. J. Dairy Sci. 92:2572-2579.

Cramer, G., K. D. Lissemore, C. L. Guard, K. E. Leslie, and D. F. Kelton. 2009b. Herd-level risk factors for seven different foot lesions in Ontario Holstein cattle housed in tie stalls or free stalls. J. Dairy Sci. 92:1404-1411.

de Jesús Argáez-Rodríguez, F., D. W. Hird, J. Hernández de Anda, D. H. Read, and A. Rodríguez-Lainz. 1997. Papillomatous digital dermatitis on a commercial dairy farm in Mexicali, Mexico: Incidence and effect on reproduction and milk production. Prev. Vet. Med. 32:275-286.

Dohoo, I., W. Martin, and H. Stryhn. 2003. Veterinary Epidemiologic Research. 1st ed. University of Prince Edward Island, Charlottetown, PE, Canada.

Döpfer, D., M. Holzhauer, and M. van Boven. 2012. The dynamics of digital dermatitis in populations of dairy cattle: Model-based estimates of transition rates and implications for control. Vet. J. 193:648-653.

Döpfer, D., A. Koopmans, F. A. Meijer, I. Szakáll, Y. H. Schukken, W. Klee, R. B. Bosma, J. L. Cornelisse, A. J. A. M. van Asten, and A. A. H. M. ter Huurne. 1997. Histological and bacteriological evaluation of digital dermatitis in cattle, with special reference to spirochaetes and Campylobacter faecalis. Vet. Rec. 140:620-623.

Ettema, J., S. Østergaard, and A. R. Kristensen. 2010. Modelling the economic impact of three lameness causing diseases using herd and cow level evidence. Prev. Vet. Med. 95:64-73.

Ettema, J. F., N. Capion, and A. E. Hill. 2007. The association of hoof lesions at claw trimming with test-day milk yield in Danish Holsteins. Prev. Vet. Med. 79:224-243.

Ettema, J. F., and J. E. P. Santos. 2004. Impact of age at calving on lactation, reproduction, health, and income in first-parity Holsteins on commercial farms. J. Dairy Sci. 87:2730-2742.

Fourichon, C., H. Seegers, N. Bareille, and F. Beaudeau. 1999. Effects of disease on milk production in the dairy cow: A review. Prev. Vet. Med. 41:1-35.

Frankena, K., J. G. C. J. Somers, W. G. P. Schouten, J. V. van Stek, J. H. M. Metz, E. N. Stassen, and E. A. M. Graat. 2009. The effect of digital lesions and floor type on locomotion score in Dutch dairy cows. Prev. Vet. Med. 88:150-157.

Green, L. E., J. Borkert, G. Monti, and N. Tadich. 2010. Associations between lesion-specific lameness and the milk yield of 1,635 dairy cows from seven herds in the Xth region of Chile and implications for management of lame dairy cows worldwide. Anim. Welf. 19:419-427.

Green, L. E., V. J. Hedges, Y. H. Schukken, R. W. Blowey, and A. J. Packington. 2002. The impact of clinical lameness on the milk yield of dairy cows. J. Dairy Sci. 85:2250-2256.

Greiner, R., L. Patterson, and O. Miller. 2009. Motivations, risk perceptions and adoption of conservation practices by farmers. Agric. Syst. 99:86-104.

Hernandez, J., and J. K. Shearer. 2000. Efficacy of oxytetracycline for treatment of papillomatous digital dermatitis lesions on various anatomic locations in dairy cows. J. Am. Vet. Med. Assoc. 216:1288-1290.

Hernandez, J., J. K. Shearer, and D. W. Webb. 2001. Effect of lameness on the calving-to-conception interval in dairy cows. J. Am. Vet. Med. Assoc. 218:1611-1614.

Hernandez, J., J. K. Shearer, and D. W. Webb. 2002. Effect of lameness on milk yield in dairy cows. J. Am. Vet. Med. Assoc. 220:640-644

Holzhauer, M., C. J. Bartels, D. Döpfer, and G. van Schaik. 2008. Clinical course of digital dermatitis lesions in an endemically infected herd without preventive herd strategies. Vet. J. 177:222-230.
Holzhauer, M., C. Hardenberg, C. J. Bartels, and K. Frankena. 2006. Herd- and cow-level prevalence of digital dermatitis in the Netherlands and associated risk factors. J. Dairy Sci. 89:580-588.

Leach, K. A., H. R. Whay, C. M. Maggs, Z. E. Barker, E. S. Paul, A K. Bell, and D. C. J. Main. 2010a. Working towards a reduction in cattle lameness: 1 . Understanding barriers to lameness control on dairy farms. Res. Vet. Sci. 89:311-317.

Leach, K. A., H. R. Whay, C. M. Maggs, Z. E. Barker, E. S. Paul, A. K. Bell, and D. C. J. Main. 2010b. Working towards a reduction in cattle lameness: 2. Understanding dairy farmers' motivations. Res. Vet. Sci. 89:318-323.

Losinger, W. C., and A. J. Heinrichs. 1997. An analysis of age and body weight at first calving for Holsteins in the United States. Prev. Vet. Med. 32:193-205.

Manske, T., J. Hultgren, and C. Bergsten. 2002. Prevalence and interrelationships of hoof lesions and lameness in Swedish dairy cows. Prev. Vet. Med. 54:247-263.

Massey, F. J., Jr. 1951. The Kolmogorov-Smirnov test for goodness of fit. J. Am. Stat. Assoc. 46:68-78.

McInerney, J. P., K. S. Howe, and J. A. Schepers. 1992. A framework for the economic analysis of disease in farm livestock. Prev. Vet. Med. 13:137-154.

Nielsen, B. H., P. T. Thomsen, L. E. Green, and J. Kaler. 2012. A study of the dynamics of digital dermatitis in 742 lactating dairy cows. Prev. Vet. Med. 104:44-52.

Pavlenko, A., C. Bergsten, I. Ekesbo, T. Kaart, A. Aland, and L. Lidfors. 2011. Influence of digital dermatitis and sole ulcer on dairy cow behaviour and milk production. Animal 5:1259-1269.

Rajala-Schultz, P. J., Y. T. Gröhn, and C. E. McCulloch. 1999. Effects of milk fever, ketosis, and lameness on milk yield in dairy cows. J. Dairy Sci. 82:288-294.

Read, D. H., and R. L. Walker. 1998. Papillomatous digital dermatitis (footwarts) in California dairy cattle: Clinical and gross pathologic findings. J. Vet. Diagn. Invest. 10:67-76.

Relun, A. 2011. Assessment of measures to control digital dermatitis in dairy herds [Efficacité des mesures de maîtrise de la dermatite digitée dans les troupeaux bovins laitiers]. PhD Thesis. Oniris, Nantes-Atlantic National College of Veterinary Medicine, Food Science and Engineering, Nantes, France.

Relun, A., R. Guatteo, P. Roussel, and N. Bareille. 2011. A simple method to score digital dermatitis in dairy cows in the milking parlor. J. Dairy Sci. 94:5424-5434.

Relun, A., A. Lehebel, N. Bareille, and R. Guatteo. 2012. Effectiveness of different regimens of a collective topical treatment using a solution of copper and zinc chelates in the cure of digital dermatitis in dairy farms under field conditions. J. Dairy Sci. 95:3722-3735.

Somers, J. G., K. Frankena, E. N. Noordhuizen-Stassen, and J. H. Metz. 2003. Prevalence of claw disorders in Dutch dairy cows exposed to several floor systems. J. Dairy Sci. 86:2082-2093.

Somers, J. G., K. Frankena, E. N. Noordhuizen-Stassen, and J. H. Metz. 2005a. Risk factors for digital dermatitis in dairy cows kept in cubicle houses in the Netherlands. Prev. Vet. Med. 71:11-21.

Somers, J. G., W. G. Schouten, K. Frankena, E. N. NoordhuizenStassen, and J. H. Metz. 2005b. Development of claw traits and claw lesions in dairy cows kept on different floor systems. J. Dairy Sci. 88:110-120.

Warnick, L. D., D. Janssen, C. L. Guard, and Y. T. Grohn. 2001. The effect of lameness on milk production in dairy cows. J. Dairy Sci 84:1988-1997.

Wells, S. J., L. P. Garber, and B. A. Wagner. 1999. Papillomatous digital dermatitis and associated risk factors in US dairy herds. Prev. Vet. Med. 38:11-24. 